\title{
Physician Burnout, Engagement and Career Satisfaction in a Large Academic Medical Practice
}

\author{
Sandhya K. Rao, MD; Timothy G. Ferris, MD, MPH; Michael K. Hidrue, MBA; Sara R. Lehrhoff, MS; \\ Sarah Lenz, MS; James Heffernan, MBA; Kathleen E. McKee, MD, MPH; and \\ Marcela G. del Carmen, MD, MPH
}

\begin{abstract}
Objective: To determine ( $I$ ) if engagement among physicians impacted plans to stay in current role and job satisfaction, (2) what factors impact engagement and burnout, and (3) the relationship between engagement and burnout. Burnout has been described as a syndrome characterized by depersonalization, emotional exhaustion, and a sense of low personal accomplishment resulting in decreased effectiveness at work. Engagement may be regarded as the antonym to burnout and has been described as a connection to one's work characterized by dedication, vigor, and absorption.
\end{abstract}

Design: We extracted data from an academic practice-wide survey conducted at two time-points and evaluated physician burnout and engagement. We used the Maslach Burnout Inventory and the Utrecht Work Engagement Scale to evaluate the association between burnout and engagement and the impact of engagement on mitigating the effect of burnout in a large physician academic faculty practice.

Setting: Large academic practice

Participants: Academic physicians

Methods: The authors conducted a hospital-wide physician practice survey in 2014 and 2017 assessing physician burnout and engagement.

Results: Of eligible physicians ( $n=1882), 92.0 \%$ completed a survey. High levels of engagement and burnout were shown in $59.5 \%$ and $45.6 \%$, respectively. Compared to physicians with high levels of engagement and low levels of burnout, physicians with low engagement and low burnout were less satisfied with their career $(O R=0.20,95 \% \mathrm{Cl}=0.1 \mathrm{I}-0.35)$ and less likely to stay in their current role $(\mathrm{OR}=0.52,95 \% \mathrm{Cl}=0.37-0.73)$. Among physicians with high levels of burnout, highly engaged physicians were more satisfied $(\mathrm{OR}=0.21 ; 95 \% \mathrm{Cl}=0.12-0.36$ vs $\mathrm{OR}=0.08 ; 95 \% \mathrm{Cl}=0.05-0.12)$ and more likely to stay in their career $(\mathrm{OR}=0.34 ; 95 \% \mathrm{Cl}=0.25-0.45$ vs $\mathrm{OR}=0.27 ; 95 \% \mathrm{Cl}=0.2 \mathrm{I}-0.34)$ than non-engaged physicians.

Conclusion: Engaged physicians have higher career satisfaction. There are many actionable ways to improve engagement.

Keywords: Physicians; Engagement; Burnout; Career satisfaction

Corresponding Author: Marcela G. del Carmen, MD, MPH, Massachusetts General Hospital Physicians Organization, 55 Fruit Street, Bulfinch 205E , Boston, Massachusetts 02II4 ,Tel: (617) 726-1940, Fax: (6I7) 724-6898, Email: mdelcarmen@ partners.org
Received: July 4, 2019

Ist revision received: August 23, 2019

2nd revision received: August 29, 2019

Accepted: September 9, 2019 
$\mathrm{P}$ hysician burnout has been described extensively in the peer-reviewed literature. ${ }^{1}$ Maslach and colleagues ${ }^{2}$ defined burnout as a syndrome characterized by depersonalization, emotional exhaustion, and a sense of low personal accomplishment resulting in decreased effectiveness at work. Although the loss of professional precision and compassion accompanying this constellation of symptoms can be devastating for individual patients, the loss of collective productivity can be even more threatening to communities that rely on ready access to high-quality clinical care. This has been demonstrated in several studies that capture how burnout can negatively impact quality and safety of care. ${ }^{3-8}$

High burnout rates among physicians have also been associated with loss of commitment and engagement. ${ }^{9-13}$ Engagement can be conceived as the antonym to burnout and has been described as a connection to one's work characterized by dedication, vigor, and absorption. ${ }^{14}$ Some authors have suggested measuring well-being not with the pathologic framing of burnout but rather the more aspirational rubric of engagement with the aim to identify work factors that can protect against often unavoidable drivers of burnout. ${ }^{15}$ Studies show that engagement can be protective of burnout and that organizations and practices that invest in programs promoting engagement can mitigate burnout in their providers. ${ }^{14-19}$

To date, most studies characterizing physician well-being have used the Maslach Burnout Inventory, ${ }^{2}$ and few researchers have used the Utrecht Work Engagement Scale (UWES), a validated instrument for measuring workplace engagement, on physicians..$^{20-22}$ Our institution conducts a survey across the entire academic practice every two years. We saw an increase in burnout from $41 \%$ in 2014 to $45 \%$ in 2017 . Given this rise, we embarked on this study, using a less frequently used tool to measure engagement, to further elucidate the association between burnout and engagement and the impact of engagement on mitigating the effect of burnout in a large physician academic faculty practice. Although a series of studies have previously documented the relationship between burnout and career engagement, few have included large academic medical practices and are limited by the use of less vetted instruments to measure engagement and low response rates. Our survey is designed to guide institutional leadership in priorities based on responses and it is part of the organizations Quality Incentive Program. With this study, we intended to expand on previous studies in the literature by including a large heterogenous

Table 1: Distribution of Respondents by Demographics and Burnout/Engagement Status (Source: Authors' analysis of the data)

\begin{tabular}{|c|c|c|c|c|c|}
\hline \multirow[b]{2}{*}{ Variable } & \multirow[b]{2}{*}{ N (\%) } & \multicolumn{2}{|c|}{ Engagement ${ }^{\mathrm{a}}$} & \multicolumn{2}{|c|}{ Burnout $^{b}$} \\
\hline & & $\begin{array}{l}\text { Engaged } \\
\mathrm{N}(\%)\end{array}$ & $P$ value & $\begin{array}{l}\text { Burned-out } \\
\mathrm{N}(\%)\end{array}$ & $P$ value \\
\hline Gender & & & $<0.0001$ & & 0.0003 \\
\hline Male & $962(51.1)$ & $612(63.6)$ & & $404(42.0)$ & \\
\hline Female & 759 (40.3) & 435 (57.3) & & $362(47.7)$ & \\
\hline Prefer not to say & $161(8.6)$ & $72(44.7)$ & & $93(57.8)$ & \\
\hline Race & & & 0.0013 & & 0.003 \\
\hline Asian & $266(14.1)$ & $163(61.3)$ & & $117(44.0)$ & \\
\hline White & $1334(70.9)$ & $816(61.2)$ & & $587(44.0)$ & \\
\hline Others $^{c}$ & $282(15.0)$ & $140(49.7)$ & & $155(55.0)$ & \\
\hline Career Stage & & & 0.229 & & 0.0094 \\
\hline Early ( $\leq 10 \mathrm{y})$ & $819(43.5)$ & 5469 (57.3) & & $399(48.7)$ & \\
\hline Middle (11-20 y) & $518(27.5)$ & $315(60.8)$ & & $240(46.3)$ & \\
\hline Late $(>20 \mathrm{y})$ & $545(29.0)$ & $335(61.5)$ & & $220(40.4)$ & \\
\hline Specialty & & & 0.046 & & $<0.001$ \\
\hline ERAPS $^{d}$ & $336(17.9)$ & $194(57.7)$ & & $138(41.1)$ & \\
\hline Medicine & $1117(59.4)$ & $673(60.3)$ & & $499(44.7)$ & \\
\hline Primary Care & $251(13.3)$ & $134(53.4)$ & & $153(61.0)$ & \\
\hline Surgical & $178(9.5)$ & $118(66.3)$ & & 69 (38.8) & \\
\hline
\end{tabular}

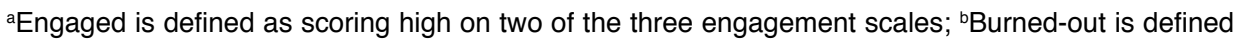
as score high on two of the three burnout scales; 'Other race includes: black/African American, American Indian/Native Alaskan, Native Hawaiian/Pacific Islander, and Others. The number of respondents for these groups were small and we combined them into one group for the analysis; ${ }^{\mathrm{d} E R A P s}=$ emergency medicine, radiology, anesthesia, and pathology 


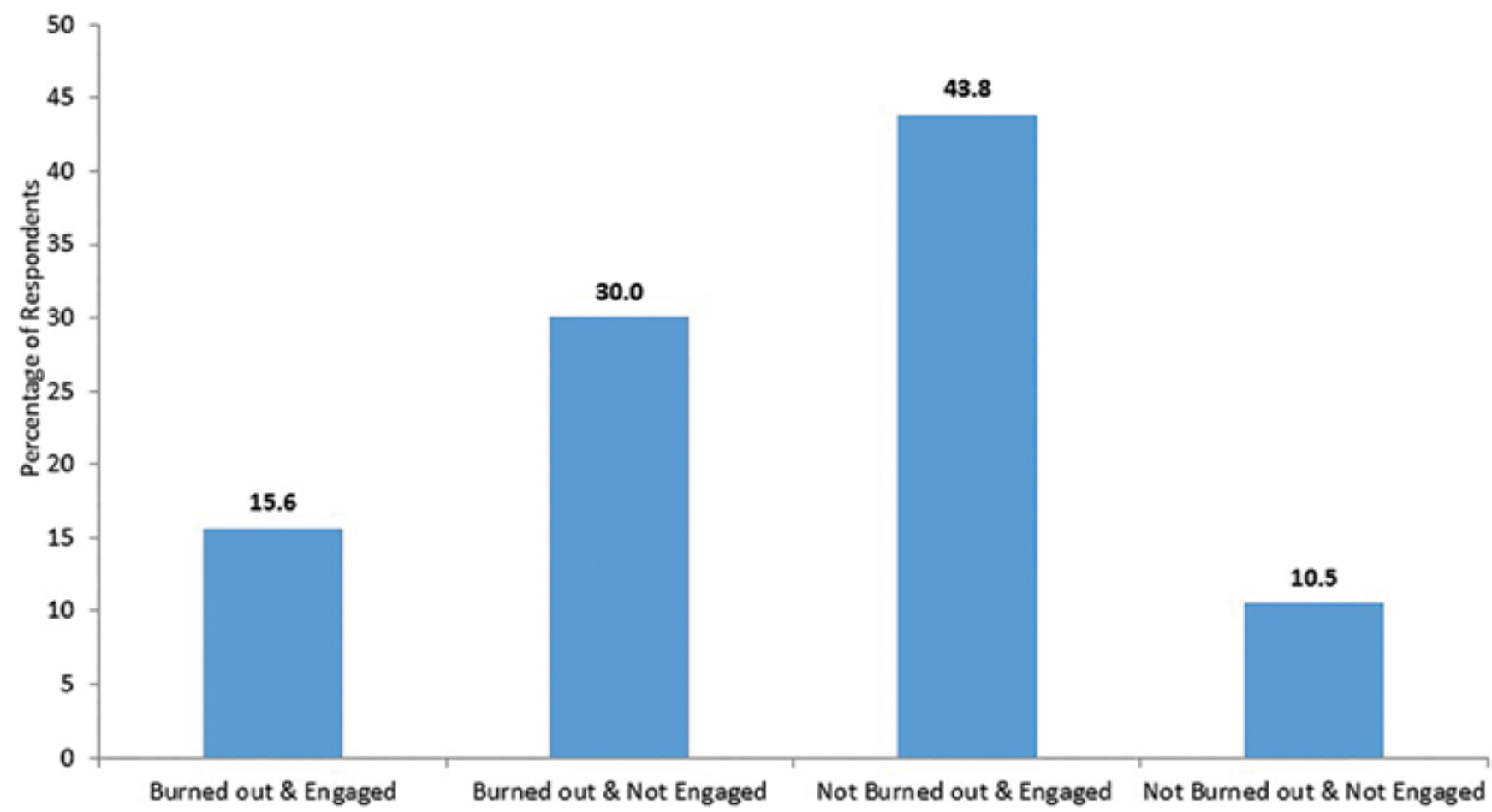

Figure 1. Distribution of respondents by engagement-burnout status

academic practice inclusive of 16 clinical departments, using a validated instrument for measuring engagement, in a survey with a historically high response rate.

We used the Maslach Burnout Inventory and the Utrecht Work Engagement Scale to report on the association between burnout and engagement and the impact of engagement on mitigating the effect of burnout in a large physician academic faculty practice.

\section{Methods}

Data were extracted from the 2017 Massachusetts General Physicians Organization survey. This study was approved by the Partners human research committee. This is a biennial survey administered to physicians comprising the faculty practice at Massachusetts General Hospital. Qualifying physicians earn a financial incentive for completing the survey, which is part of the organization's Quality Incentive Program. ${ }^{23,24}$ The goals of the survey are to evaluate the functioning of our clinical enterprise within and across departments, reflect on the progress made on current organizational priorities, and evaluate hospital leadership. ${ }^{23,24}$ The 2017 survey included questions assessing four domains of interest: (1) career and compensation satisfaction; (2) wellbeing; (3) administrative workload; and (4) leadership and diversity. ${ }^{24}$

\section{Outcome Measures}

To explore the relationship between burnout and engagement, we constructed the following four binary outcome measures.
- Burnout: measured using the Maslach Burnout InventoryGeneral Service (MBI-GS). Physicians were considered 'burned-out' if they scored at extreme in two of three subscales: high in exhaustion or cynicism, and low in professional efficacy. ${ }^{2}$

- Work engagement: assessed using the Utrecht Work Engagement Scale. $^{20}$ Physicians were considered 'engaged' if they scored high on two of three subscales: vigor, dedication, and absorption.

- Career satisfaction: measured using responses to the question "How satisfied are you with your career as a physician?" Physicians were considered "satisfied" if they chose one of the top two responses on a five-point Likert scale: very satisfied, satisfied, neutral, dissatisfied, or very dissatisfied. ${ }^{24}$

- Intention to stay at current role: assessed using a question asking physicians about their career plans for the next three years. Physicians who indicated that they would continue in their current role were defined as 'staying.'

Based on the burnout and engagement outcomes defined above, we created an interaction variable that resulted in four mutually-exclusive groups: (1) burned out and engaged; (2) burned out and not engaged; (3) not burned out and engaged, and; (4) not burned out and not engaged. The reference group selected was physicians with low levels of burnout and high levels of engagement. The interaction variable was used to measure the degree of association (overlap) between the two outcomes and assess the moderating effect of engagement on the impact of burnout on career satisfaction and intention to stay at current role. 
Table 2: Odds Ratio Estimates Predicting the Likelihood of Engagement and Burnout (Source: Authors' analysis of the data)

\begin{tabular}{|c|c|c|c|c|}
\hline \multirow[b]{2}{*}{ Predictors } & \multicolumn{2}{|c|}{ Engagement } & \multicolumn{2}{|c|}{ Burnout } \\
\hline & Odds Ratio & {$[95 \% \mathrm{Cl}]$} & Odds Ratio & {$[95 \% \mathrm{Cl}]$} \\
\hline \multicolumn{5}{|l|}{ Gender (ref=Male) } \\
\hline Female & 0.91 & $(0.72-1.14)$ & 0.93 & $(0.74-1.17)$ \\
\hline Other & 0.77 & $(0.51-1.19)$ & 1.06 & $(0.69-1.63)$ \\
\hline \multicolumn{5}{|l|}{ Race (ref=White) } \\
\hline Asian & 0.92 & $(0.68-1.26)$ & 1.11 & $(0.82-1.50)$ \\
\hline Others & 0.92 & $(0.66-1.28)$ & 1.10 & $(0.79-1.53)$ \\
\hline \multicolumn{5}{|l|}{ Career Stage (ref=late) } \\
\hline Early ( $\leq 10$ y) & 0.70 & $(0.53-0.92)$ & 1.87 & $(1.42-2.47)$ \\
\hline Middle (11-20 y) & 1.04 & $(0.78-1.38)$ & 1.29 & $(0.97-1.71)$ \\
\hline \multicolumn{5}{|l|}{ Specialty (ref=medicine) } \\
\hline ERAPs & 0.82 & $(0.62-1.09)$ & 0.87 & $(0.66-1.16)$ \\
\hline PCP & 1.22 & $(0.88-1.69)$ & 1.42 & $(1.02-1.97)$ \\
\hline Surgery & 1.22 & $(0.83-1.78)$ & 0.79 & $(0.55-1.15)$ \\
\hline Career Misfit & 0.67 & $(0.47-0.96)$ & 1.21 & $(0.85-1.73)$ \\
\hline \multicolumn{5}{|l|}{ Satisfaction with } \\
\hline Opportunity to consult with Peers & 1.63 & $(1.41-1.89)$ & 0.71 & $(0.61-0.82)$ \\
\hline CME Support & 1.31 & $(1.15-1.49)$ & 0.82 & $(0.71-0.93)$ \\
\hline Work Load & 1.60 & $(1.43-1.78)$ & 0.54 & $(0.48-0.60)$ \\
\hline Trusted Advisor & 1.27 & $(1.16-1.39)$ & 0.79 & $(0.72-0.86)$ \\
\hline
\end{tabular}

ERAPs, emergency medicine, radiology, anesthesia, and pathology; PCP, primary care physicians; CME, Continuing Medical Education

Each model was adjusted for basic demographics and selected work factors. For the burnout and engagement models, we adjusted for demographics (gender, race/ethnicity, career stage), specialty, career misfit ( $<20 \%$ of time spent on activity physician finds most meaningful), and selected work characteristics (satisfaction with Continuing Medical Education [CME] opportunity, workload, having a trusted advisor, and opportunity to consult with peers). ${ }^{25}$ For models characterizing career satisfaction and intention to stay at current role, we adjusted for demographics (gender, race/ ethnicity, career stage), specialty, and burnout-engagement interaction.

The Chi-square test was used for univariate comparison and multivariate logistic regression to assess the predictors of each outcome variable. A significance level of less than 5\% was used to establish statistical significance. All statistical analyses were performed using SAS version 9.4 (SAS Institute Inc., Cary, North Carolina).

\section{Results}

Of the 2,031 physicians in the MGPO who received the survey, $92.66 \%(\mathrm{n}=1882)$ responded. A total of $40.3 \%$ $(\mathrm{n}=759)$ were female, $51.1 \%(\mathrm{n}=962)$ were male, and $8.6 \%$ $(n=161)$ preferred not to specify their gender. Of all respondents, $59.4 \%(\mathrm{n}=1117)$ were medical specialists, and $43.5 \%(n=819)$ had been in practice for 10 years or less (Table $1)$.

\section{Burnout and Engagement}

Low levels of burnout and high levels of engagement were reported by $43.8 \%(n=825)$ of respondents. High levels of burnout and low levels of engagement were reported by $30.0 \%$ $(n=565)$ of respondents while $15.6 \%(n=294)$ of respondents reported both high levels of burnout and high levels of engagement. Providers reporting both low levels of burnout and low levels of engagement consisted of $10.5 \%(n=198)$ of those responding (Figure 1).

Univariate analysis showed a statistically significant difference in engagement and burnout by gender, race/ethnicity, and specialty. Although career stage did not predict engagement, early-career physicians ( $\leq 10$ years) reported higher levels of burnout $(P=0.009$; Table 1$)$.

In the multivariate analysis controlling for demographics and selected workplace factors (Table 2), neither gender nor race/ ethnicity predicted burnout or engagement. However, earlycareer physicians were more likely to report high levels of burnout $(\mathrm{OR}=1.87,95 \% \mathrm{CI}=1.42-2.47)$ and low levels of 


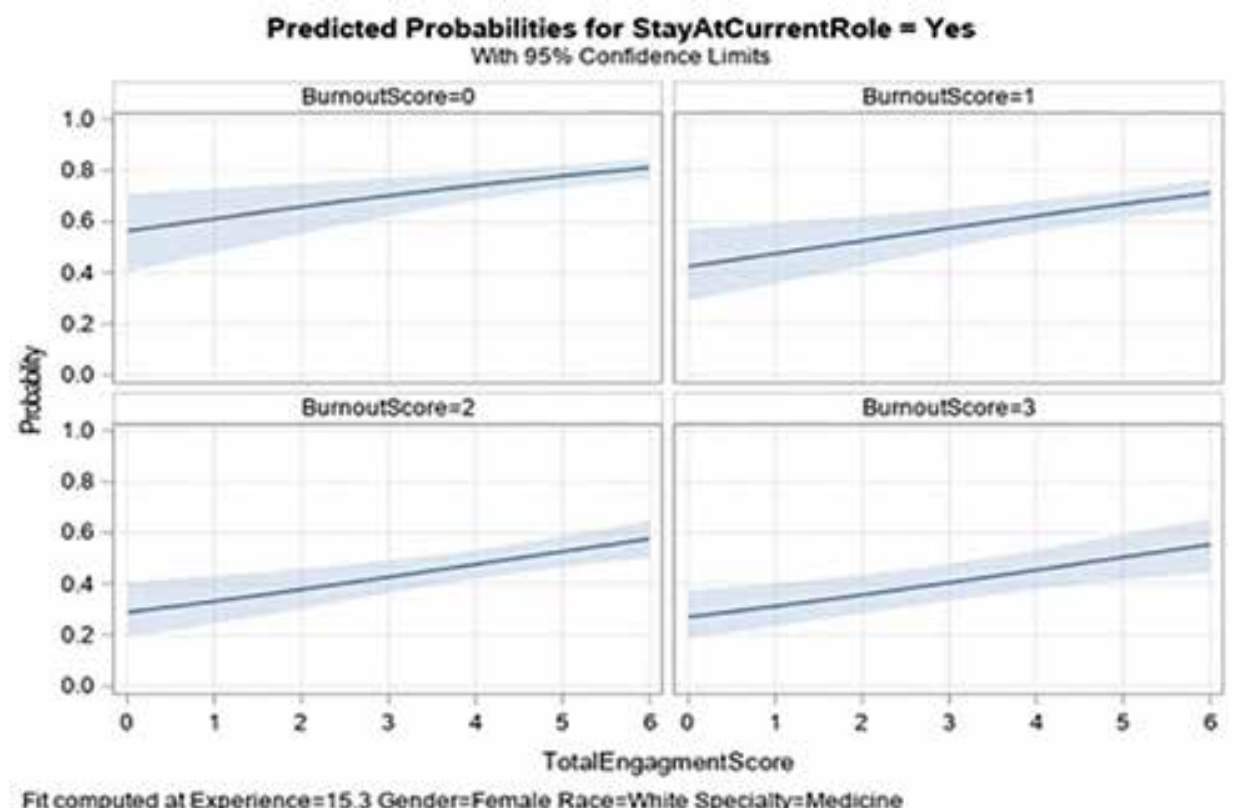

Figure 2A. Examining the effect of engagement on the likelihood of staying in current role. The figure shows the impact of engagement on the likelihood of staying at current role for different levels of Burnout. The Predicted Probabilities are based on a logistic model adjusting for gender, race, specialty, experience (number of years since training), levels of burnout and engagement. For illustration purpose, engagement and burnout are specified differently in this model. Engagement is measured using the total engagement score, which is the average score of the three engagement subscales. It is specified as a continuous variable and has values that range from zero to six. Levels of burnout is measured as the sum of high score for the three burnout subscales and has four levels ( $3=$ high in all three scales, $2=$ high in two scales, $1=$ high in one scale, and $0=$ not high in any scale). The plots are computed for a white-female physician in the department of medicine who had 15 years of experience (the relationship between levels of burnout and levels of engagement are similar for other groups).

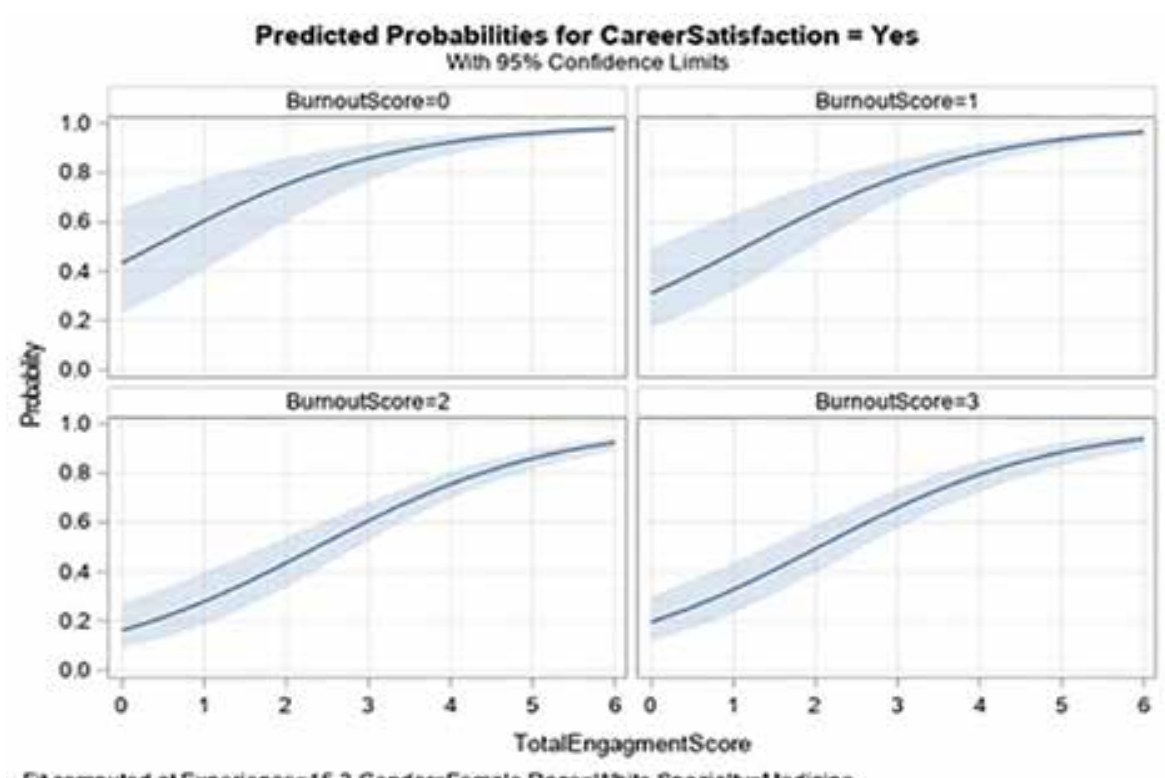

Fitcomputed at Experience= 15,3 GenderaFemale RacesWhite SpecialtyaMedicine

Figure 2B. Examining the effect of engagement on the likelihood of career satisfaction. The figure shows the impact of engagement on the probability of career for different levels of Burnout. The Predicted Probabilities are based on a logistic model that adjusted for gender, race, specialty, experience (number of years since training), levels of burnout and engagement. For illustration purpose, engagement and burnout are specified differently in this model. Engagement is measured using the total engagement score, which is the average score of the three engagement subscales. It is specified as a continuous variable and has values that range from zero to six. Levels of burnout is measured as the sum of high score for the three burnout subscales and has four levels (3=high in all three scales, $2=$ high in two scales, $1=$ high in one scale, and $0=$ not high in any scale). The plots are computed for a white-female physician in the department of medicine who had 15 years of experience (the relationship between levels of burnout and levels of engagement are similar for other groups). 
engagement $(\mathrm{OR}=0.70,95 \% \mathrm{CI}=0.53-0.92)$. Compared to physicians in medicine, primary care physicians (PCPs) were more likely to report high levels of burnout $(\mathrm{OR}=1.42,95 \%$ $\mathrm{CI}=1.02-1.97)$. Although career misfit did not predict burnout, physicians with career misfit were more likely to have low levels of engagement $(\mathrm{OR}=0.67,95 \% \mathrm{CI}=0.47-0.96)$. Finally, higher satisfaction with CME support, ability to consult peers, workload, and having a trusted advisor were associated with low levels of burnout and high levels of engagement.

Table 3 presents multivariate regression analysis predicting the impact of burnout-engagement interaction on career satisfaction and staying at current role. After controlling for burnout, engagement improves career satisfaction and likelihood of staying in current role. Among physicians with low levels of burnout, non-engaged physicians were less satisfied with their career $(\mathrm{OR}=0.20,95 \% \mathrm{CI}=0.11-0.35)$ and less likely to stay in their current role $(\mathrm{OR}=0.52,95 \% \mathrm{CI}=$ $0.37-0.73$ ) than engaged physicians. Similarly, among physicians with high levels of burnout, engaged physicians were more satisfied with their career $(\mathrm{OR}=0.21 ; 95 \% \mathrm{CI}=0.12$ 0.36 vs $\mathrm{OR}=0.08 ; 95 \% \mathrm{CI}=0.05-0.12)$ and more likely to stay in their career $(\mathrm{OR}=0.34 ; 95 \% \mathrm{CI}=0.25-0.45$ vs $\mathrm{OR}=0.27$; $95 \% \mathrm{CI}=0.21-0.34)$ than non-engaged physicians.

To illustrate the mitigating effect of engagement, we also plotted the predicted probabilities of career satisfaction and staying at current role as a function of the levels of burnout and total engagement score (Figures 2A and 2B). For each level of burnout, the likelihood of staying in current role and career satisfaction increase as a function of total engagement score.

\section{Discussion}

Although the relationship between burnout and engagement has been previously identified in the literature, this study makes a significant contribution to our understanding of this association in several ways. Most researchers employ quality of life, work-life balance scales, or the mini-Z survey. ${ }^{26-28} \mathrm{We}$ employed the Utrecht Work Engagement Scale, which is validated instrument for measuring workplace engagement on physicians. The mini-Z survey usually measures the emotional exhaustion component of burnout. The Utrecht Work Engagement Scale measures vigor, dedication, and absorption. ${ }^{20-22}$ These metrics may be a more appropriate assessment of career engagement. The current study is also unique in that it represents a heterogenous academic medical practice, comprised of 16 clinical departments, and thus, elucidates a broader experience than previously reported, expanding beyond a single discipline in medicine. Our results describe the experience of an academic practice inclusive of physicians across different career stages, and expanding primary care, specialty medicine, surgical disciplines and both hospital- and ambulatory-based practices.

Furthermore, the survey response rate we report in the current study is $92 \%$, much higher than response rates usually reported for this type of research. Our sample size is also large, with 1,882 respondents. In the meta-analysis carried out by Panagioti and colleagues, ${ }^{29}$ inclusive of 47 studies and 42,473 physicians, the median number of recruited physicians was 243 , significantly lower than our participant sample size.

Our study suggests that work place engagement - which has been shown to be important in other professions-is also crucial for physicians. We found that engaged physicians at our organization, regardless of their level of burnout, have higher levels of career satisfaction and are more likely to stay in their current role. Thus, promoting engagement may be as important as mitigating burnout. Although physicians with low levels of burnout and low levels of engagement fared better than those who were burned out, physicians who were not burned out but reported high levels of engagement were twice as satisfied with their careers as those with low levels of both burnout and engagement.

Others have reported similar findings. In the meta-analysis conducted by Panagioti and colleagues, ${ }^{29}$ which included 47 studies, burnout was associated with low professionalism, especially among residents and early-career physicians. In the present study, early-career physicians ( $\leq 10$ years) also reported higher levels of burnout $(P=0.009)$. This finding represents an opportunity for healthcare organizations to support physicians transitioning from trainees to professionals, and as suggested by others, may prove to be the most effective intervention for burnout prevention and reduction. ${ }^{29-35}$ As suggested by Slavin, ${ }^{30}$ health care leadership should focus efforts in increasing physician engagement in satisfying professional activities. These initiatives should include experiences that increase meaning, sense of purpose, connectivity and sense of being part of a unit larger than the individual. ${ }^{30}$ Individual physicians should focus their efforts on achieving meaning in their vocation and calling. ${ }^{30}$

Implications of the association between burnout and engagement may extend beyond maintaining an appropriate level of professional satisfaction. Low professionalism has been associated with poorer quality of care (OR, 2.31;95\% $\mathrm{CI}, 1.87-2.85)$ and reduced patient satisfaction (OR, 2.28; $95 \%$ CI, 1.42-3.68). ${ }^{29}$

As has been suggested by others, we found burnout and engagement often function divergently, but not always. ${ }^{26,27}$ If burnout and engagement were opposite experiences, we would expect all respondents to sort into either the highburnout, low-engagement category or the low-burnout, highengagement category. However, we observed that a quarter of our respondents did not sort into these expected categories. For these somewhat neutral respondents, not being burned out did not automatically translate into high levels of engagement and being engaged did not necessarily protect them from burnout. 
We found that both engagement and burnout are driven by themes of connectedness, mentorship, and continued learning. This is supported extensively by other studies on physician burnout and non-physician studies on engagement. ${ }^{28-30}$ Although much attention in the field of physician burnout has been focused on the electronic health record (EHR) and administrative burden on wellbeing, we found that considerable gains could potentially be achieved by creating programs in which physicians can have time and opportunity to connect with one another, as well as adequate support and resources for continued education and career development. Programs designed to decrease burnout and increase engagement should focus on vulnerable clinicians, including early-career providers - who may find it challenging to secure mentorship and continued learning opportunities - and those assigned to spend time traveling to multiple sites of care-for whom connectivity to other colleagues may be difficult to attain.

Career fit, a concept introduced by Shanafelt et al, ${ }^{25}$ is defined as having $20 \%$ of time dedicated to one's preferred professional activity. Previous studies have associated it with reduced burnout levels. Interestingly, we found in our population, that career fit was associated with improved engagement, but not negatively associated with burnout. Career fit is a more challenging aspect of physician life, requiring effective mentorship, availability of opportunities, and in many cases, resources to provide physicians with time and support to pursue specific interests. Enabling physicians to dedicate 20\% of their time toward their passions seems like a small investment for the potentially large effect on increased physician retention.

Our study is limited primarily by the fact that it is a single center study. Furthermore, our study focused on academic physicians, so our findings may not be generalizable to broader physician communities.

\section{Conclusion}

Our study demonstrates that to achieve maximum levels of career satisfaction and retention, we need to address both burnout and engagement. In general, this relies on addressing themes of connectedness and continued learning. Engagement is uniquely driven by having time to devote to the most satisfying aspects of one's career. Institutions need to design and implement initiatives that identify activities maintaining high-levels of engagement and protect time to dedicate to those interests.

\section{References}

1. Freudenberger HJ. Staff burn-out. J Social Issues. 1974;30(1):159-165.

2. Maslach C, Jackson SE, Leiter MP. Maslach burnout inventory manual, 3rd edn. Palo Alto: Consulting Psychologists Press, 1996.

3. West CP, Huschka MM, Novotny PJ, et al. A ssociation of perceived medical errors with resident distress and empathy: a prospective longitudinal study. JAMA. 2006;296(9):10711078.
4. Williams ES, Manwell LB, Konrad TR, Linzer M. The relationship of organizational culture, stress, satisfaction, and burnout with physician-reported error and suboptimal patient care: results from the MEMO study. Health Care Manage Rev. 2007;32(3):203-212.

5. West CP, Tan AD, Habermann TM, Sloan JA, Shanafelt TD. Association of resident fatigue and distress with perceived medical errors. JAMA. 2009;302(12):1294-1300.

6. Shanafelt TD, Balch CM, Bechamps G, et al. Burnout and medical errors among American surgeons. Ann Surg. 2010; 251(6):995-1000.

7. Linn LS, Brook RH, Clark VA, Davies AR, Fink A, Kosecoff J. Physician and patient satisfaction as factors related to the organization of internal medicine group practices. Med Care. 1985;23(10):1171-1178

8. Haas JS, Cook EF, Puopolo AL, Burstin HR, Cleary PD, Brennan TA. Is the professional satisfaction of general internists associated with patient satisfaction? J Gen Intern Med. 2000;15(2):122-128.

9. Dewa CW, Jacobs P, Thanh NX, Loong D. An estimate of the cost of burnout on early retirement and reduction in clinical hours of practicing physicians in Canada. BMC Health Services Research. 2014;14(254):1-9.

10. Dewa CS, Loong D, Bonato S, Thanh NX, Jacobs P. How does burnout affect physician productivity? A systematic literature review. BMC Health Services Research. 2014;14(325):1-10.

11. Swensen S, Kabcenell A, Shanafelt T. Physician-organization collaboration reduces physician burnout and promotes engagement: The Mayo Clinic experience. J Healthc Manag. 2016;61(2):105-27.

12. Shanafelt, TD, Balch CM, Bechamps GJ, et al. Burnout and career satisfaction among American surgeons. Ann Surg. 2009;250(3):463-471.

13. Shanafelt, T, Raymond, M, Kosty, M, et al. Satisfaction with work-life balance and the career and retirement plans of US oncologists. J Clin Oncol. 2014;32(11):1127-1135.

14. Shanafelt T, Noteworthy J. Executive leadership and physician well-being: Nine organizational strategies to promote engagement and reduce burnout. Mayo Clin Proc. 2017;92(1):129-146.

15. Eckleberry-Hunt J, Kirkpatrick H, Barbera T. The problems with burnout research. Academic Medicine. 2018;93:67-370.

16. Shimazu A, Schaufeli WB. Work engagement: an emerging concept in occupational health psychology. Biosci Trends. 2008;2(1):2.

17. Maslach C, Leiter MP. Understanding the burnout experience: recent research and its implications for psychiatry. World Psychiatry. 2016;15(2):103-111.

18. Shanafelt TD. Enhancing meaning in work: a prescription for preventing physician burnout and promoting patient-centered care. JAMA. 2009;302(12):1338-1340.

19. Konrad TR, Williams ES, Linzer M, et al, for SGIM Career Satisfaction Study Group. Measuring physician job satisfaction in a changing workplace and a challenging environment. Med Care. 1999;37(11):1174-1182.

20. Schaufeli W, Bakker A. (2004). Utrecht work engagement scale: Preliminary manual. Utrecht: Occupational Health Psychology Unit, Utrecht University. Available at: https:// www.wilmarschaufeli.nl/publications/Schaufeli/Test $\% 20$ Manuals/Test_manual_UWES_English.pdf. Last accessed: Feb 28, 2020.

21. Schaufeli WB, Salanova M, Gonzalez-Romá V, Bakker AB. The measurement of engagement and burnout: A confirmative analytic approach. Journal of Happiness Studies. 2002;3(1):71-92. 
22. Schaufeli W.B, Bakker AB, Salanova M. The measurement of work engagement with a short questionnaire: A cross-national study. Educational and Psychological Measurement.

2006;66(4):701-716. Available at: https://doi. org/10.1177\%2F0013164405282471. Last accessed: Feb 28, 2020.

23. Meyer GS, Torchiana DF, Colton D, et al. The use of modest incentives to boost adoption of safety practices and systems. In: Henriksen K, Battles JB, Keyes MA, et al, eds. Advances in Patient Safety: New Directions and Alternative Approaches (Volume 3: Performance and Tools). Rockville, MD: Agency for Healthcare Research and Quality;2008. http://www.ncbi. nlm.nih.gov/books/NBK43652/. Accessed February 13, 2019.

24. Rao SK, Kimball AB, Lehrhoff SR, et al. The impact of administrative burden on academic physicians: Results of a hospital-wide physician survey. Acad Med. 2017;92(2):237243.

25. Shanafelt TD, West CP, Sloan JA, et al. Career fit and burnout among academic faculty. Arch Intern Med. 2009;169(10):990995.

26. Linzer M, Manwell LB, Williams ES, et al; MEMO (Minimizing Error, Maximizing Outcome) Investigators. Working conditions in primary care: physician reactions and care quality. Ann Intern Med. 2009;151(1):28-36, W6-W9.

27. Linzer M, Poplau S, Babbott S, et al. Worklife and wellness in academic general internal medicine: Results from a national survey. J Gen Intern Med. 2016;(9):1004-10

28. Mehta LS, Lewis SJ, Duvernoy CS, et al, on behalf of the American College of Cardiology Women in Cardiology Leadership Council. Burnout and career satisfaction among U.S. cardiologists. J Am Coll Cardiol. 2019;73(25):33453348.

29. Panagioti M, Geraghty K, Johnson J, et al. Association between physician burnout and patient safety, professionalism, and patient satisfaction: A systematic review and meta-analysis. JAMA Intern Med. 2018;178(10):13171330.

30. Slavin S. Preventing physician burnout: satisfaction or something more? Isr J Health Policy Res. 2019;8(1):34.

31. Hoff T, Carabetta S, Collinson GE. Satisfaction, burnout, and turnover among nurse practitioners and physician assistants: A review of the empirical literature. Med Care Res Rev. 2019;76(1):3-31.

32. Ghazanfar H, Chaudhry MT, Asar ZU, Zahid U. Compassion satisfaction, burnout, and compassion fatigue in cardiac physicians working in tertiary care cardiac hospitals in Pakistan. Cureus. 2018;10(10):e3416.

33. Gribben JL, MacLean SA, Pour T, Waldman ED, Weintraub AS. A cross-sectional analysis of compassion fatigue, burnout, and compassion satisfaction in pediatric emergency medicine physicians in the United States. Acad Emerg Med. 2019;26(7):732-743.

34. Truchot J, Chauvin A, Hutin A, Leredu T, Plaisance P, Yordanov Y. Burnout and satisfaction among young emergency physicians. Eur J Emerg Med. 2018 Dec;25(6):445-446

35. Essary AC, Bernard KS, Coplan B, et al. Burnout and job and career satisfaction in the physician assistant profession: A review of the literature. NAM Perspectives. 2018. Available at: https://nam.edu/wp-content/uploads/2018/11/Burnout-andSatisfaction-in-the-PA-Profession.pdf. Accessed: August 29, 2019.

\section{Author Affiliations}

Sandhya Rao, MD*; Timothy G. Ferris, MD, MPH†; Michael K. Hidrue, PhD ; Sara R. Lehrhoff, MSई; Sara

Lenz, MD\|; James Heffernan, MBA |; Kathleen E. McKee, MD, MPH\#; Marcela G. del Carmen, MD, MPH**

*Senior Medical Director for Population Health Management, Partners Health; Assistant Professor of Psychiatry, Harvard Medical School, Boston, MA $\dagger$ Chief Executive Officer, Massachusetts General Physicians Organization; Professor of Medicine, Harvard Medical

School, Boston, MA

$\neq$ Senior Health Economist, Massachusetts General

Physicians Organization, Boston, MA

$\S$ Director of Physician Programs, Massachusetts General

Hospital Physicians Organization, Boston, MA

"Chief of Staff, Massachusetts General Physicians

Organization, Boston, MA

-Chief Financial Officer, Massachusetts General Physicians Organization, Boston, MA

\#Massachusetts General Physicians Organization;

Department of Neurology, Massachusetts General Hospital,

Boston, $M A$

**Chief Medical Officer, Massachusetts General Physicians Organization; Professor of Obstetrics, Gynecology and

Reproductive Biology, Harvard Medical School, Boston, MA 